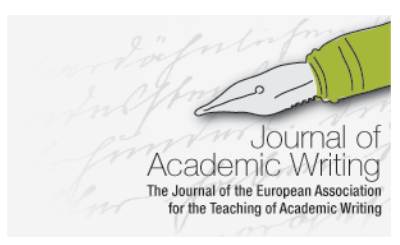

Journal of Academic Writing

Vol. 10 No 1 WINTER 2020, pages 113-127 https://doi.org/10.18552/joaw.v10i1.613

\title{
Disciplinary Writing Tutors at Work: A Study of the Character of the Feedback Provided on Academic Writing at the BA Programmes at the Humanities Department
}

\author{
Vibeke Christensen \\ University of Southern Denmark, Denmark \\ Peter Hobel \\ University of Southern Denmark, Denmark
}

\begin{abstract}
New students struggle to develop academic writing skills during transition to university. To meet this challenge, the Humanities department at the University of Southern Denmark implemented a research and development project to increase feedback to student writers. In the project, graduate students were trained as disciplinary writing tutors, and subsequently provided feedback on undergraduates' assignments. The study presented in this article examines the feedback offered by the disciplinary writing tutors. As researchers, we ask, "What characterises the feedback offered by the disciplinary writing tutors?" The study is positioned in a sociocultural framework that draws on theories of disciplinary and academic literacy. Data was collected in four bachelor's degree programmes and consists of the feedback given by the tutors and interviews with the tutors conducted at the end of the tutoring. Principal results indicate that the feedback on the students' texts is distributed at the text layer of content and structure and the text layer of formalities. Feedback at the text layer of sentences is almost absent. Feedback on the writing and learning processes is limited. The discipline-specific feedback occurs as indications in the feedback to the BA students and is made clearer when comparing feedback in different programmes. The feedback the writing tutors provide demonstrates an understanding of academic writing as academic socialisation.
\end{abstract}

\section{Introduction}

New students find the transition to university demanding and challenging, as they encounter unanticipated expectations related to writing (Lillis \& Turner, 2001; Prior \& Bilbro, 2012). This is particularly the case for students who do not come from an academic background ${ }^{1}$ (Lillis, 2002). The University of Southern Denmark (SDU), which is the setting for this study, is characterised as a "sweeper university" with approximately one third of its students lacking an academic background. The academic staff at the university have expressed concern regarding the general quality of the students' academic writing. Academic writing is central to academic and disciplinary enculturation (Curry \& Lillis, 2003; Prior \& Bilbro, 2012), and supporting the development of students' academic writing also supports their academic learning.

Danish undergraduate programmes do not include mandatory courses in written composition, and consequently, academic writing skills must be taught by the various disciplines. Thus, our

\footnotetext{
${ }^{1}$ According to The Danish Ministry of Higher Education and Science, in 2018, 38\% of the students at University of Southern Denmark were the first generation in their families to be university students.
} 
research and development project was embedded in the tradition of writing in the disciplines (WID, e.g. Shanahan \& Shanahan, 2012), and aimed to strengthen and support academic writing and writing instruction in bachelor degree programmes. Central to the project was a selection of MA students who provided feedback to BA students in the same programme. The MA students were designated as disciplinary writing tutors and affiliated with a specific discipline in the programme. During a three-day workshop, the tutors discussed disciplinary and general academic writing, feedback, and writing pedagogy, and were trained as tutors. The tutors' previous writing assignments were used as workshop material. They deconstructed these assignments together, to discover and characterise the disciplinary discourse of each discipline, and to discover differences and similarities between the discourses of the disciplines. Lecturers joined the workshop on the third day, and the tutors and the lecturers planned the tutoring for the various discipline together. The project and this study are positioned in a sociocultural framework that draws on theories of disciplinary literacy (Shanahan \& Shanahan, 2012) and academic literacies (Lea \& Street, 1998). Students are considered agents who adopt disciplinary discourses and enter a disciplinary community through academic writing (Ivanič, 2004; Lillis \& Turner, 2001; Prior \& Bilbro, 2012).

In this article, we examine the character of the feedback provided by the disciplinary writing tutors, which leads to the research question: What characterises the feedback offered by disciplinary writing tutors? In addition, we discuss the writing tutors' underlying understanding of academic writing and the principal learning opportunities provided to the tutees.

A good deal of research on supporting the development of academic writing has been conducted in the tradition of writing across the curriculum (WAC). Adams (2011) confirms that both tutors and tutees benefit from using peer tutors, and Gladstein (2008) finds that tutoring strengthens inquiry and dialogue, whereas Wingate (2019) investigates the proportions of a dialogic approach and scaffolding in tutoring. Tutors must negotiate ideas and construct meaning in cooperation with the students to avoid prescriptive, monologic teaching. A few studies investigate the use of generalists versus specialists as tutors. One study documents success in connecting generalist tutors to a course (Marr \& Misser, 2008), whereas another (Severino \& Traschel, 2008) does not conclude whether the tutor should be a generalist in writing or a specialist in the discipline-specific academic content. Instead, Severino and Traschel find more similarities than differences in undergraduate writing assignments across disciplines. Several studies agree on the necessity of training writing tutors for their task, though they are carefully selected, but most of the studies do not describe workshops for training tutors (Gladstein, 2008; Herkner et al., 2012; Marcoux et al., 2012; Marr \& Misser, 2008; Moberg, 2010; Okawa et al., 2010). Two studies are exceptions. Adams describes training that consists of self-directed reading, group discussions, and observation (Adams, 2011), and Simpson, Clemens, Killingworth and Ford describe training as mentoring during supervision (Simpson et al., 2015).

O'Neill's (2008) study describes WID at the outset and investigates "the potential role of peer tutors and writing fellows in higher education in the United Kingdom". (O'Neill, 2008, p. 1) He finds that the strongest students seem to receive the greatest benefit from the writing tutoring. O'Neill's study is similar to ours, but does not address the content of the feedback it discusses. Another study that is similar to ours is Blåsjö and Josephson's (2018). They investigate writing in teacher education, and find that teacher and peer feedback address the discipline's discourses (the text's macro-area) and formal elements - spelling and so on (the text's microarea). On the other hand, feedback that addresses the meso-area of the text - for example, sentence-level construction of valid explanations and arguments - is almost entirely absent.

The use of peer feedback in symmetrical relationships is well-grounded in the literature. Topping $(2005 ; 2009)$ finds that peer feedback or peer assessment promotes learning for both the student giving and the student receiving feedback. He adds that criteria for the assignments must be negotiated and discussed among the students, and feedback must address the negotiated criteria. Crossmann and Kite (2012) and Graham and Perin (2007) recommend taking the deconstruction of model texts (e.g. assignments written by older students) as the starting point when establishing criteria. In our study, the relationship between tutors and tutees 
is not completely symmetrical, but still we consider the research outcomes from studies on peer feedback relevant.

The research on peer tutoring in writing in the disciplines seems to be investigated primarily from the perspective of a writing centre, and to some extent is associated with mandatory writing courses. The focus and form of the feedback provided by tutors are examined to a limited extent. This study aims to begin to fill the knowledge gap concerning the content of the feedback offered by discipline-specific writing tutors.

\section{Feedback and academic writing}

In this section we first present our understanding of academic writing and feedback. Next, we present our understanding of writing and the writing process. By combining feedback and writing theory, we present a matrix to be used in our analysis. We will continuously discuss the short-term and long-term learning potential of the feedback.

Lea and Street (1998) present three models of academic writing in higher education: Study skills, Academic socialisation and Academic literacies. The status of the text varies in each model. In academic writing as study skills, writing is conceptualised in terms of generic technical and instrumental skills. In academic writing as academic socialisation, writing is conceptualised as a medium for presentation. Academic writing is socialisation into the academic discourse, and the student must learn norms and practices related to academic texts and writing in general, and in specific disciplines. In academic writing as academic literacies writing is viewed as a social practice and negotiation of meaning-making. The text is part of this negotiation, which develops in power structures and involves identity work. Academic literacies include a critical view of the academic content and the status of writing itself. Academic writing as a set of study skills is embedded in academic socialisation, which is embedded in academic literacies. This model was developed in response to research on student writing, but Lea and Street (1998) also consider it applicable to teaching, as it establishes a framework for reflecting on practices. When used as framework for teaching, the models encourage teachers to reflect on various aspects of writing (Lea \& Street, 2006), which may lead to an emphasis on various elements of the writing process and the text. An investigation of feedback on writing and texts in the framework of academic literacies requires an understanding of the text that embraces the three conceptions.

Black and Wiliam offer a model that encompasses five strategies for developing formative assessment in the classroom (Black \& Wiliam, 2009, p. 8). One of the strategies is "Activating students as instructional resources for one another", and another is the teacher "Providing feedback that moves learners forward" (Black \& Wiliam, 2009, p. 8). They relate feedback to learning intentions. Hattie and Timperley focus on the individual learner, and define feedback as "information provided by an agent (...) regarding aspects of one's performance or understanding" (Hattie \& Timperley, 2007, p. 81). Hattie and Timperley relate feedback to learning goals or success criteria. According to both Black and Wiliam, and Hattie and Timperley, feedback answers the questions concerning the goal or direction of the performance or understanding, the actual status of the performance, and how to make further progress (Black \& Wiliam, 2009; Hattie \& Timperley, 2007), but their time horizon seems different, and based on different terminology. Whereas Hattie and Timperley's success criteria are specific, and therefore short-term, Black and Wiliam's learning intentions offer the opportunity to also function as long-term directions. In this study, feedback is conceptualised as information that targets both the student's writing, to improve the text, and his or her development and learning about writing in a longer perspective. Feedback may be given at four levels: task, process, selfregulation and self-level ${ }^{2}$ (Hattie \& Timperley, 2007, p. 87). Feedback at the task level is information about how well a task, including the content it covers, is being carried out. Feedback

\footnotetext{
${ }^{2}$ Feedback at the self-level is omitted from this study because of the ambiguity regarding its influence on learning (Hattie \& Timperley, 2007). This is also mentioned to the writing tutors during their training.
} 
at the process level addresses how to approach the work processes when executing the task. The self-regulation level includes both personal factors, such as motivation and engagement, and monitoring one's own learning.

The theories mentioned above describe optimal conditions and circumstances for providing feedback leading to learning. Thus, the predominant perspective is on the feedback provider, and short-term and long-term potential for learning are conceptualised in terms of the provider's intentions. But the recipient of the feedback does not always recognise it as such (e.g. Carless, 2006), despite agreement on the criteria, and consequently may not use it. In other cases, the feedback is interpreted differently than intended, and used differently by the learner. Therefore, the learning potential may appear different to the learner. In this study, we focus on the intention.

Feedback at the task level is provided to the academic text. Dysthe et al. (2000) consider writing a situated activity that encompasses the writing process and its product, that is, the text. Feedback should address both. They present five textual layers on which feedback at the task level may be given:

1. writing situation, context of the writing, purpose and audience

2. content and structure, including structural components

3. sentences/clauses

4. word choice

5. formal elements: spelling, punctuation and use of references

Besides learning to write, the student learns the disciplinary academic content when writing in the programme (Dysthe et al., 2000; Lea \& Street, 1998; Shanahan \& Shanahan, 2012). In other words, writing involves two parallel processes: the short-term production of the actual text and the long-term learning. Besides, during writing, enculturation happens (Prior \& Bilbro, 2012).

Combining Dysthe et al.'s (2000) understanding of writing with the three levels of feedback provides a model for analysing and characterising feedback. Feedback at task level targets the assignment as such, and is conceptualised as feedback on the text, that is, the five text layers. Feedback at the writing-process level corresponds with Hattie and Timperley's process level, and addresses the execution of an actual assignment. Feedback at these levels targets the short-term goals of learning and learning to write by commenting on and suggesting changes to a given text. Depending on how the feedback is used, it also has the potential to scaffold long-term learning. Feedback at the self-regulation level is, in Hattie and Timperley's description, the student monitoring and regulating the work on the task (Hattie \& Timperley, 2007, p. 93). This monitoring has the potential to target ongoing learning, to clarify and support academic learning, and learning to write, specifically, in a broader perspective. However, in Hattie and Timperley's description, attention to how to learn is more strongly emphasised than attention to what was learned. Emphasising the latter calls for elaboration of Hattie and Timperley's description to meet the role of the academic content of the learning and the role of writing in the social practice in academic literacy. Thus, we expand the level of self-regulation with meta-reflection that emphasises and enhances the importance of appraising academic content and the role of writing. Feedback at the meta-reflection and self-regulation level intentionally addresses long-term learning regarding both writing and discipline-specific learning. Table 1 provides a summary of our combination of feedback levels and text layers. 
Table 1

Model for analysing the tutors' feedback

\begin{tabular}{|l|l|l|}
\hline \multicolumn{2}{|c|}{ Feedback levels } \\
\hline $\begin{array}{l}\text { Task } \\
\text { (feedback on the text layers) }\end{array}$ & $\begin{array}{l}\text { Process } \\
\text { (feedback on the writing } \\
\text { process) }\end{array}$ & $\begin{array}{l}\text { Meta-reflection and self- } \\
\text { regulation } \\
\text { (feedback that addresses learning } \\
\text { and future writing) }\end{array}$ \\
\hline $\begin{array}{l}\text { Writing situation, purpose } \\
\text { and recipient }\end{array}$ & $\begin{array}{l}\text { Feedback supporting the } \\
\text { writing process from the first } \\
\text { including structural } \\
\text { components } \\
\text { for example, ongoing revision } \\
\text { or improving writing in the } \\
\text { given genre. }\end{array}$ & $\begin{array}{l}\text { Feedback that encourages the } \\
\text { recipient to monitor appropriate } \\
\text { features of his or her text and } \\
\text { writing process, to be used in } \\
\text { future I writing. Feedback at this } \\
\text { level targets texts, writing and } \\
\text { learning. An example would be } \\
\text { the characteristics of } \\
\text { argumentation specific to the } \\
\text { discipline in question. }\end{array}$ \\
$\begin{array}{l}\text { Spelling, punctuation and use } \\
\text { of references }\end{array}$ & \begin{tabular}{l} 
\\
\hline
\end{tabular} & \\
\hline
\end{tabular}

The feedback levels and text layers were presented to, and discussed with the tutors at the training workshop, and they practised giving feedback at all levels and text layers using their own assignments as practice material.

\section{Methodology}

We conducted qualitative ethnographic research during the autumn of 2018 and the spring of 2019. The research methods included observation, interviews and document gathering. The participating programmes' key activities, such as presenting the writing tutors, presenting the assignment to the BA students, the tutors' workshop and the tutors' oral feedback to the whole class were observed. Once the tutoring was concluded, some of the BA students turned in their assignments, and we collected the tutors' written feedback. We also conducted semi-structured interviews (Kvale \& Brinkmann, 2014) with the tutors. They were asked to discuss their experiences and to evaluate the tutoring. We transcribed the interviews. The written feedback to assignments, the transcribed interviews and the tutors' notes on the oral feedback were analysed as documents (Bowen, 2009), and coded to reflect the feedback levels and text layers (see Table 1).

Programmes for this study were chosen among the total number of programmes participating in the training workshop because they presented different exam forms, exam products and class sizes, as shown in Table 2. 
Table 2

Outline of the participating programmes, tutors, and students

\begin{tabular}{|c|c|c|c|c|c|c|}
\hline \multirow[t]{2}{*}{ Programme } & American Studies & \multicolumn{2}{|c|}{ Design Culture and Economics } & \multicolumn{2}{|c|}{ Media Science } & $\begin{array}{l}\text { Intercultural } \\
\text { Pedagogy and } \\
\text { Danish as L2 }\end{array}$ \\
\hline & \multicolumn{6}{|c|}{ Training workshop for disciplinary writing tutors } \\
\hline Discipline & $\begin{array}{c}\text { American History, } \\
\text { Culture and } \\
\text { Language }\end{array}$ & $\begin{array}{l}\text { History and } \\
\text { Analysis of } \\
\text { Fashion, } \\
\text { Fashion as a } \\
\text { Commodity }\end{array}$ & $\begin{array}{l}\text { History and } \\
\text { Analysis of } \\
\text { Design, } \\
\text { Design as a } \\
\text { Commodity }\end{array}$ & $\begin{array}{c}\text { Media } \\
\text { Culture and } \\
\text { History }\end{array}$ & $\begin{array}{l}\text { Media Theory } \\
\text { and Analysis }\end{array}$ & Cultural Analysis II \\
\hline $\begin{array}{l}\text { Number of } \\
\text { tutors }\end{array}$ & 3 & 2 & 3 & 2 & 2 & 2 \\
\hline $\begin{array}{l}\text { Approx. BA } \\
\text { students }\end{array}$ & 45 & 30 & $2 \times 30$ & 80 & 120 & 30 \\
\hline Exam & $\begin{array}{l}\text { Portfolio: } \\
\text { two in-class } \\
\text { assignments and an } \\
\text { end-of-semester } \\
\text { assignment. }\end{array}$ & \multicolumn{2}{|c|}{$\begin{array}{l}\text { Written assignment set by the } \\
\text { lecturer. }\end{array}$} & $\begin{array}{l}\text { Written } \\
\text { assignment } \\
\text { set by the } \\
\text { lecturer. }\end{array}$ & $\begin{array}{l}\text { Written } \\
\text { outline } \\
\text { (synopsis) of a } \\
\text { topic selected } \\
\text { by the } \\
\text { student, and } \\
\text { an oral } \\
\text { presentation. }\end{array}$ & $\begin{array}{l}\text { Classroom } \\
\text { Participation during } \\
\text { the semester. }\end{array}$ \\
\hline $\begin{array}{l}\text { Tutors' } \\
\text { supervision } \\
\text { during class }\end{array}$ & $\begin{array}{l}\text { Tutors in charge of } \\
\text { group discussions } \\
\text { when an } \\
\text { assignment is } \\
\text { presented; } \\
\text { Tutors offer } \\
\text { feedback while the } \\
\text { assignments are } \\
\text { being written } \\
\text { Written feedback } \\
\text { on the assignment; } \\
\text { Tutors offer oral } \\
\text { feedback to the } \\
\text { completed } \\
\text { assignment }\end{array}$ & \multicolumn{2}{|c|}{$\begin{array}{l}\text { In-class workshop on an } \\
\text { assignment; oral feedback } \\
\text { offered; } \\
\text { Peer feedback; } \\
\text { After assignment submission, } \\
\text { joint feedback to entire classes; } \\
\text { Individual written feedback on } \\
\text { the assignment; } \\
\text { Oral feedback offered } \\
\text { afterwards. }\end{array}$} & $\begin{array}{l}\text { Workshop } \\
\text { on writing } \\
\text { short } \\
\text { articles on } \\
\text { the } \\
\text { literature } \\
\text { read for the } \\
\text { class; } \\
\text { Feedback } \\
\text { offered } \\
\text { during and } \\
\text { after the } \\
\text { workshop. }\end{array}$ & $\begin{array}{l}\text { Written } \\
\text { feedback on } \\
\text { texts for oral } \\
\text { presentations; } \\
\text { Oral feedback } \\
\text { on the written } \\
\text { outline for the } \\
\text { exam. }\end{array}$ & $\begin{array}{l}\text { In-class written and } \\
\text { oral feedback on } \\
\text { three assignments; } \\
\text { Tutors organise } \\
\text { peer feedback. }\end{array}$ \\
\hline Data & $\begin{array}{l}\text { Written feedback } \\
\text { from two tutors to } \\
\text { students } \\
\text { Interviews with } \\
\text { tutors. }\end{array}$ & $\begin{array}{l}\text { Written } \\
\text { feedback from } \\
\text { the tutors to } \\
\text { three students. } \\
\text { Tutors' notes on } \\
\text { oral feedback to } \\
\text { the whole class. } \\
\text { Interview with } \\
\text { the tutors; }\end{array}$ & $\begin{array}{l}\text { Interviews } \\
\text { with tutors. }\end{array}$ & $\begin{array}{l}\text { Interviews } \\
\text { with tutors. }\end{array}$ & $\begin{array}{l}\text { Interview with } \\
\text { tutors. }\end{array}$ & $\begin{array}{l}\text { Written feedback to } \\
\text { individual students; } \\
\text { Interview with } \\
\text { tutors; } \\
\text { Tutors' notes on } \\
\text { oral feedback to the } \\
\text { whole class. }\end{array}$ \\
\hline
\end{tabular}

Note: The table describes participants and the various ways of organising the supervision, partly depending on the exam form. Data from the four programmes were coded according to the feedback levels and text layers. This article presents the qualitative analysis of the data from the programmes and disciplines shown in the two first columns (in black font).

Data was collected with the participants' consent. In the analysis, the tutors' names are pseudonyms. Below, we present an analysis of data from the American Studies and the Design 
Culture and Economics with a Fashion specialisation programmes only, because when we coded all the collected data, these two programmes yielded the thickest data, and although there are differences in the numbers of students and the exam forms, they reflected the distribution of feedback on text layers and feedback levels, as may be seen in Table 3 .

During the coding process, some individual comments in the feedback addressed various text layers and were treated as feedback at various layers.

\section{Analysis and Results}

In this section, we first present the coding of written feedback and notes to oral feedback and comments in the interviews on feedback for the entire data set (row 1 and 2 in table 3), then the coding from the American Studies (row 3 and 4 I table 3) and the Design Culture and Economics with a Fashion specialisation programmes (row 5 and 6 in table 3). As may be seen, the two programmes chosen for closer analysis (row 3-6) do not deviate from the trend of the entire data set (row 1-2). Before considering the analysis of the feedback on the two programmes, we investigate some general patterns.

\section{Table 3}

Coding of the written feedback and the statements on the feedback

\begin{tabular}{|c|c|c|c|c|c|c|c|c|}
\hline & $\begin{array}{l}\text { Feedback } \\
\text { focus I } \\
\text { Feedback } \\
\text { source }\end{array}$ & $\begin{array}{l}\text { Writing } \\
\text { situation, } \\
\text { purpose } \\
\text { and } \\
\text { recipient }\end{array}$ & $\begin{array}{l}\text { Content } \\
\text { and } \\
\text { structure }\end{array}$ & $\begin{array}{l}\text { Sentences/ } \\
\text { clauses }\end{array}$ & $\begin{array}{l}\text { Word } \\
\text { choices }\end{array}$ & $\begin{array}{l}\text { Spelling, } \\
\text { punctuation } \\
\text { and } \\
\text { sources of } \\
\text { references }\end{array}$ & Process & $\begin{array}{l}\text { Meta- } \\
\text { reflection } \\
\text { and self- } \\
\text { regulation }\end{array}$ \\
\hline 1 & $\begin{array}{l}\text { Written } \\
\text { feedback } \\
\text { from tutors } \\
\text { in the four } \\
\text { programmes } \\
\text { (cf. table 2) }\end{array}$ & 2 & 59 & 7 & 7 & 50 & 14 & 3 \\
\hline 2 & $\begin{array}{l}\text { Feedback } \\
\text { statements } \\
\text { in interviews } \\
\text { with tutors } \\
\text { from the } \\
\text { four } \\
\text { programmes } \\
\text { (cf. table 2) }\end{array}$ & 1 & 30 & 3 & 1 & 13 & 15 & 8 \\
\hline 3 & $\begin{array}{l}\text { American } \\
\text { Studies } \\
\text { Written } \\
\text { feedback } \\
\text { from the } \\
\text { tutors }\end{array}$ & 1 & 7 & 0 & 3 & 6 & 5 & 0 \\
\hline 4 & $\begin{array}{l}\text { American } \\
\text { studies } \\
\text { Feedback } \\
\text { statements } \\
\text { in the } \\
\text { interviews } \\
\text { from the } \\
\text { tutors }\end{array}$ & 0 & 7 & 0 & 0 & 3 & 2 & 2 \\
\hline
\end{tabular}




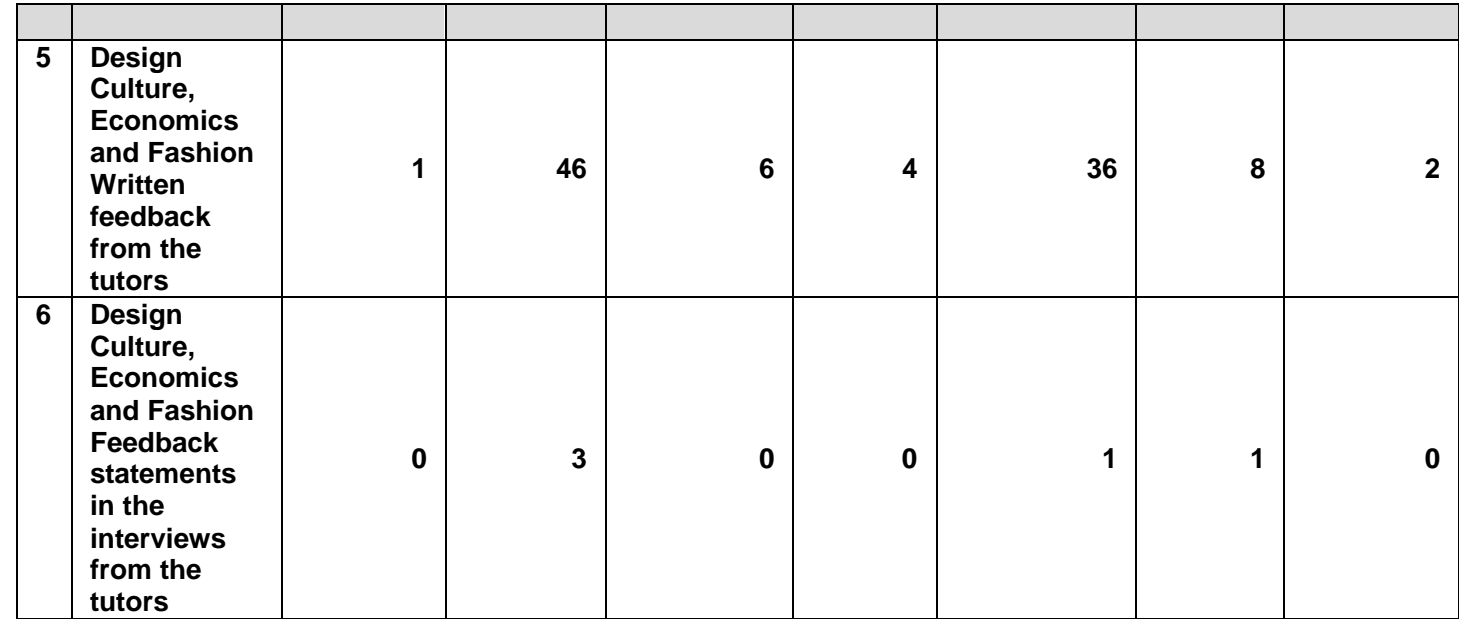

Note: The table presents the coding of the entire data set as well as the two selected programmes.

As is evident in Table 3, most feedback was offered at the task level, less at the process level and the least at the self-regulation and meta-reflection level. In the interviews, the tutors discuss feedback at the self-regulation and meta-reflection level, but provide written feedback at this level to a lesser extent. Focusing on the distribution of the feedback at the task level, this pattern is notable. Most of the feedback targets the layers of content and structure, and spelling, punctuation and use of references in the text.

The tutors from the Design Culture and Economics with a Fashion specialisation programme provide more feedback than the tutors from American Studies (cf. Table 3), because they offer many brief comments. This seems to be due to these tutors' personal style. Despite differences in amount, the distribution of the types of feedback is similar. They focus on content, structure and formal elements. To a limited extent they focus on sentences and word choice, that is, on how an academic text is understood regarding words, sentences and connections between sentences, but they do not address the context of the writing, though the tutors were introduced to these two layers of the text (see table 1) during the three-day workshop.

Taking these findings as our starting point, we will examine the feedback provided. The next two sections begin with an analysis of feedback at the task level, starting with the firstmentioned layer (see Table 1) and continuing with the other layers. This is followed by analyses of feedback at the process level, and at the self-regulation and meta-reflection level.

\section{Tutoring students at the department of American Studies}

When providing task-level feedback, the tutors from the department of American Studies provided the most feedback on the structure and content layer, as is evident in table 3. The central structural element is the thesis statement. Lily comments on this: "In the thesis statement you state, 'This paper will argue that strong profit thinking, a lack of environmental awareness and of public responsibility, made the connection between businesses and society bad'. Fundamentally, this is a good thesis statement, and specifying what affects the relationship between business and society is very good, too. However, using the word 'bad' makes the thesis statement normative. Be a little more concrete when specifying the relationship, for example, 'This paper will argue that profit-driven thinking, and lack of environmental awareness and of public responsibility caused American society to distrust businesses, which created a tense relationship between the two.' Can you see the difference? My suggestion is concrete and accurate. Using "bad" is looser, calling for interpretation".

Lily offers a reformulation and demonstrates what a thesis statement must look like when writing in the discipline in question. Lily acknowledges that the student has produced a thesis statement but suggests adjustments that may indicate a specific disciplinary discourse. She suggests changing "connection" to "relationship" - apparently regarding this as the correct concept in an American Studies discourse - and she specifies accepted ways of describing bad relationships in terms of distrust and tension. In this way, she urges the tutee to strengthen the thesis 
statement by using the terminology and concepts of the discipline, and not everyday language, and she urges the tutee to be analytical, not normative. Thus, she propagates the jargon and framework of academic conventions (academic socialisation, using the term of Lea and Street). She also suggests better wording. Thus, the feedback employs a discipline-specific perspective.

Filip also comments on the thesis statement when discussing the structure of a text. He writes: "A thesis statement and a presentation of the structure of the assignment are missing from your introduction. In your analysis you write about the concept of 'Robber Barons', instead of analysing the acts of the robber barons. In the conclusion you reiterate the definition of the concept, instead of discussing whether it is the right concept to use". (our italics)

Filip emphasises that an assignment includes some structural components. In the feedback he mentions the introduction/thesis statement, analysis and conclusion. Thus, Filip identifies core structural components and advises the tutee to use them.

The structure and function of textual elements are also mentioned in the interviews. In the interview, Lily says, "We reviewed some global elements ... that is, that you have to include a thesis statement". Filip adds the importance of an underlying argument and a connecting thread. Lily adds, "We discussed that the analyses were more like accounts in their first assignment. They then asked, "How can we change that?" We then provided feedforward". Thus, the tutors are aware of the differences in the purposes of the various structural components. Filip stresses the necessity of analysis but does not exemplify how it may be carried out at sentence and paragraph layers. The focus on developing the correct structure is in line with an understanding of academic writing as academic socialisation.

On the sentence layer, the tutors correct syntax errors or point out "obscure" sentences. On the word layer, the tutors underline the importance of selecting and using discipline-specific concepts (discipline-specific content). It is important to define "Robber Barons", and it is also important to use the concept in the analysis. "Bad" is not a discipline-specific concept, and commenting on another thesis statement, Filip claims that saying that "General Motor beats Ford" (our italic) is not "super academic". In American Studies you have to apply a different concept. Thus, the relationship between discipline-specific content and terminology is identified.

Much of the feedback provided at the task level addresses the layer of structure. Spelling and punctuation errors are commented on. But first and foremost, the tutors state that the students must get references straight. Two examples:

"I recommend you look into the Chicago Manual of Style".

"Furthermore, having so few references is a problem ... you must have grounds for your claims, and this is done by having references".

The first comment is feedback on correctly formatting references. In this instance it addresses improving the assignment, but also focuses on how to correctly cite references in future assignments. Though feedback on formalities, the last statement also offers feedback on the content layer, and the discipline-specific discourse is addressed: the tutee must have references to ensure that the argument is valid in the context of the discipline. Besides addressing the actual assignment, this feedback may also be categorised as meta-reflection, because the use of references is part of the argumentation in academic writing and required in future assignments. Thus, this feedback has the potential to scaffold long-term learning.

Most of the feedback addresses the task level, but feedback at the process and meta-reflection levels also occurs. Lily offers feedback at the process level when she recommends that a student spend more time on a task:

I agree on the first part of the assignment being more distinct than the last part. But I am sure you could make the whole assignment distinct if you allow yourself plenty of time on the assignment. 
The tutors also provide process feedback about where and how to seek information regarding formalities, and they stress the importance of finding the right references.

In the interview, when they evaluated their supervision, two of the tutors stated they would like to offer more feedback at the process, self-regulation and meta-reflection level:

So, two of us, Lily and I, we asked the students to reflect on something like, "what could be done better in my assignment" or "what could I do differently in my assignment" [...] that is, teaching the students things they can take away, yes, that"s it.

Susan wants the feedback to support both the student's work on the next assignment and his or her long-term learning. By asking the students to reflect on what they could do to make their assignments stronger, she and Lily even have a strategy to support long-term learning. Knowing the discipline, Susan and Lily have credibility when discussing this with the students.

\section{Tutoring students at the Department of Design, Culture and Economics with a Fashion specialisation}

When providing feedback at the task level, the tutors underline the importance of presenting theory in a specific way and using the right structure, which is feedback at the layers of content and structure. For example, Sofie writes: "You would benefit from introducing your theory more explicitly". She suggests explicating the presentation in the actual assignment, which is necessary in the discourse of the design programme. This understanding specifically addresses the writing situation and the context of the writing. Also, she implicitly addresses the function of the theory as part of the main argument. In the latter understanding, this might be feedback at the self-regulation and meta-reflection level.

Argumentation is the subject of another feedback comment. Another tutee claims that freedom and sexuality are reflected differently today than in the 1960s, and Sofie comments, "You have to give grounds for your claim", that is, the tutee must provide grounds for these claims that are accepted as valid by the discipline in question. She draws attention to the problem of having knowledge about the roles of freedom and sexuality in the history of design and fashion. Thus, Sofie addresses the discipline-specific discourse, but she does not explain how valid arguments are constructed at the sentence layer, nor does she explain how to give a valid presentation of relevant discipline-specific theory (sentence layer).

The use of photos in argumentation is specific to the design programmes. Several comments address the connection between a photo and the writing and may be comprehended as task feedback and process feedback:

In the paragraph about Karl Lagerfeld and Chanel I recommend you position the supplementary images close to the text that refers to the pictures.

You would benefit from setting the pictures of the clothes in the paragraph where you write about them. Put the pictures of the clothes in the section in which you discuss them. This is more manageable, and the reader does not have to scroll to find them.

The picture is part of the argumentation, thus the position of the picture is important for identifying it as such. Sofie tells the student how to lay out a specific part of the assignment (task feedback). Karen also emphasises the importance of using discipline-specific concepts or terminology when she suggests that a tutee replace "object" with "garment".

The foregoing examples have the potential to become feedback at the self-regulation and metareflection level if the student transfers a comment to argumentation in general. Sofie scaffolds the student in acquiring this perspective when she adds, "A photo must be situated near the textual argument as an integral part of it".

At the task level, the tutors underline the importance of structure. Andreas says he became aware that he had to give feedback on more than formal language errors: "We have moved 
from focusing on language to focusing on structure. The feedback may focus on many different problems and you have to consider what to clamp down on." Sofie admits that it is not always easy to avoid focusing on formal language errors, and stated, "Well, it is very difficult. It's harder than I thought. You know, a student who consistently omits the present-tense " $r$ "." Andreas also emphasises that the students should not confine themselves to describing a theory, but explain how to apply it: "You must indicate that you understand the theory and explain how to apply it, later".

Noting the importance of the discourse of the discipline, the tutors also become aware of the importance of academic socialisation. In contrast, when giving feedback on the sentence layer, the tutors focused on formal syntax, not on the discipline-specific discourse, and when it comes to the formal layer, the feedback focuses on source references (but not on references as part of the argument), spelling, and punctuation.

Instances of feedback at the meta-reflection and self-regulation level are limited. They are reiterated at the end of the assignments and address both future academic texts and learning. Andreas acknowledges the structure of a student's text, but adds, "Meta-communicate more and add subheads". In another comment to the same student, Andreas points out that the student has cited only a few sources, which might may the assignment too narrow or one-sided. This comment draws the attention to critical literacy.

Explicit feedback at the process level is mentioned when there is a question of how to improve assignments. In the interview, the tutors do not mention feedback at the self-regulation and meta-reflection level.

\section{Summing up}

Most of the feedback the tutors provide concerns tasks. Most feedback is offered at, and addresses the text layers of content, structure and formal elements. Though many of the examples of feedback address academic writing in general, some wordings and suggestions for using specific concepts may indicate an angle specific to a given discipline. Also, feedback on references focuses on elements specific to the academic discipline in question.

As shown in the analysis, the tutors do give feedback on process, and at the meta-reflection and self-regulation level, though to a limited extent. Most of the feedback at the process level is about how to use available resources, such as guides and Power Point presentations, revision and time allocated to the assignment. Most of the few comments given explicitly at the self-regulation and meta-reflection level concern argumentation. Depending on the student's use of the feedback, some of the comments at the task level may become feedback at the meta-reflection level.

\section{Discussion}

This discussion addresses three themes: 1 . discussion of feedback specific to a given discipline; 2. characterisation of the feedback provided; 3 . discussion and understanding of academic writing and the learning opportunities for the tutees.

The training workshop made the tutors aware that academic writing is discipline-specific, and that it is important to introduce the BA students to the discourses specific to their disciplines. Discipline-specific feedback assumes three forms: explicitly expressed in writing or oral feedback, implicitly understood in the set-up of feedback, and in comparisons of the feedback practices of the two programmes. Explicit, discipline-specific feedback is only indirectly evident. At the programme of American Studies, feedback on the wording of a thesis statement identifies acceptable ways of describing relationships between institutions and phenomena in this particular discipline. Tutors from the design programme mention the application of a theory,

${ }^{3}$ Concord error in the Danish language. 
without being specific. The explicit discipline-specific feedback would be clearer if the feedback addressed the use of theoretical concepts.

The implicit discipline-specific feedback is related to the selection of writing tutors; the writing tutors are students in the same programme as the tutees, which gives them credibility. Their sense of the prevailing discourse makes them judge the use of words that connect disciplinespecific concepts, for example, Lily suggests "relationship" instead "connection". Their awareness of the discipline-specific discourse provides them with an internalised understanding, which they bring to their supervision. This aspect of the feedback is not necessarily intentional.

Comparing the feedback provided by the writing tutors from the two programmes, the differences in the discipline-specific discourses become evident. The demands of academic argumentation are similar throughout academia, but the most important elements differ in the two programmes. Thus, where to start and how to develop and refine argumentation differs. At the programme of American studies, the phenomenon of analysis is constructed in the language only, and must be communicated in words, whereas the object of analysis in the Design programme is an artefact that is represented in the text by photos. At the programme of American studies, references seem to be central to the argument. The Design programme also requires the use of references, but understanding the way in which a photo or an element in a photo may be included in an argument is as important to the new student as is using references. This is stressed by the tutors. In other words, the development of a valid argument is specific to each discipline.

The feedback provided addresses the three levels. Most of the feedback involves the task level, the second-largest amount involves the process level, and just a little involves the selfregulation and meta-reflection level. This distribution confirms previous research findings that $1-2 \%$ of feedback addresses the self-regulation level, $25-40 \%$ addresses the process level and the rest of the feedback, that is, most of it, addresses the task level (Hattie, 2012). Though we expand Hattie and Timperley's self-regulation level with meta-reflection in our study, the amount of feedback at this level corresponds with the results of Hattie and Timperley. Feedback at self-regulation and meta-reflection level is not absent but seems to present a challenge to the tutors. This is worth mentioning because feedback at this level aims to support long-term learning, and go beyond the current assignment. We see several explanations of the distribution of the feedback. In extension of Hattie and Timperley's findings, the tutors may have never received feedback at this level. During the training course, they gain knowledge and experience of providing feedback at the self-regulation and meta-reflection levels, but they are not urged to do this in a specific way. Furthermore, no specific attention is paid to the connection between feedback at the text layers and the self-regulation and meta-reflection levels, which could help them to develop feedback practices. A final possible explanation is that the tutors who have not yet graduated do not possess the necessary perspective to be able to provide more feedback at meta-reflection level. This suggests that the content and function of the training course could bear further investigation.

The tutors' awareness of feedback at the process level may partly be a result of knowledge of the writing process, writing development and writers block, gained during the training workshop, but the context of the tutoring may offer another explanation. At the programme of American Studies, the BA students assemble a portfolio of three assignments. Two of these are written during the semester, and the third is an exam paper written at the end of the semester. Commenting on how to handle the next assignment and what to remember is clear to the tutors. At the programme of Design Culture and Economy, the tutors participated in a workshop to prepare the BA students for the written assignment in their exam, which provided them with a forward-looking perspective on writing.

At the task level of feedback, the tutors address several text layers (cf. Table 1): formalities, word choice, sentence and structure. The writing situation and the purpose of the writing are not addressed in the feedback. This is surprising, but may be due to the background of the project and the tutoring, which, among other things, support the students' enculturation in academia and discipline-specific communities through writing support. Thus, the writing 
situation is tacit, and may seem self-evident, as the BA students must write for professors/lecturers who, in a broader perspective, represent their discipline's academic community.

With reference to Blåsjö and Josephson's (2018) text areas, feedback on a text is provided mainly at the macro-area and, to a lesser degree, at the micro-area. This pattern is consistent with results of their study, which investigates a lecturer's feedback on the writing of teacher students (Blåsjö \& Josephson, 2018). In Dysthe et al.'s model (2000) the meso-area of the text covers words, sentences and part of the structural layer (2000) including cohesion and paragraphing. The limited feedback at the meso-area may be explained by the tutors' lack of experience in receiving feedback at this area, and because they have no metalanguage to express such feedback. The short presentation during the training workshop was not enough to provide them with this metalanguage, nor did they have enough experience of using it to be able to identify developmental potential, and provide feedback at this area. The tutors offered a relatively large amount of feedback at the micro-area. One possible explanation may be that they have received feedback at the micro-area throughout their own studies (e.g. Matre \& Solheim, 2015).

If we analyse the feedback through the lens of Lea and Streets' models of academic writing, the tutors seem to provide feedback based on an understanding of academic writing as study skills and academic socialisation. This understanding may be based in a focus on formal elements and content, structure and argumentation patterns as necessary for meeting the requirements of the disciplines' academic discourses. We did not find feedback that explicitly focused on writing as a social practice or as critical thinking, that is academic literacies. This finding is not so surprising as students have had limited training and are involved in one module only. The finding thus underscores the important role of teachers or programme managers, if the goal is to move towards an academic literacies perspective on writing. 


\section{References}

Adams, J. (2011). Investigating peer tutoring for academic writing support in a UK university. Journal of Academic Writing, 1(1), 110-119. https://doi.org/10.18552/joaw.v1i1.1

Black, P., \& Wiliam, D. (2009). Developing the theory of formative assessment. Educational Assessment, Evaluation and Accountability, 21(1), 5-31. https://doi.org/10.1007/s11092-008-9068-5

Blåsjö, M., \& Josephson, O. (2018). Texter och genrenormer. In P.-O. Erixon \& O. Josephson (Eds.), Kampen om texten: examensarbetet $i$ lärarutbildningen (The Struggle for the Text. Examination Papers in Teacher Education). Studentlitteratur AB.

Bowen, G. A. (2009). Document analysis as a qualitative research method. Qualitative research journal, 9(2), 27-40. https://doi.org/10.3316/QRJ0902027

Carless, D. (2006). Differing perceptions in the feedback process. Studies in Higher Education, 31(2), 219-233. https://doi.org/10.1080/03075070600572132

Crossman, J. M., \& Kite, S. L. (2012). Facilitating improved writing among students through directed peer review. Active Learning in Higher Education, 13(3), 219-229. https://doi.org/10.1177/1469787412452980

Curry, M., \& Lillis, T. (2003). Issues in academic writing in higher education. In C. Coffin (Ed.), Teaching academic writing (pp. 1-18). Routledge.

Dysthe, O., Hertzberg, F., \& Hoel, T. L. (2000). Skrive for å lære : skriving i høyere utdanning (Writing to learn: Writing in Higher Education). Abstrakt forlag.

Gladstein, J. M. (2008). Conducting research in the gray space: How writing associates negotiate between WAC and WID in an introductory biology course. Across the Disciplines, 5. https://wac.colostate.edu/docs/atd/fellows/gladstein.pdf

Graham, S., \& Perin, D. (2007). Writing next: Effective strategies to improve writing of adolescents in middle and high schools. Alliance for Excellent Education.

Hattie, J. (2012). Visible learning for teachers: maximizing impact on learning. Routledge.

Hattie, J., \& Timperley, H. (2007). The power of feedback. Review of Educational Research, 77(1), 81-112. https://doi.org/10.3102/003465430298487

Herkner, L., Pydde, M., Tschirpke, S., Girgensohn, K., \& Liebetanz, F. (2012). Paving the Way for Writing Across the Curriculum (WAC): Establishing Writing Centers and Peer Tutoring at High Schools in Germany. Across the Disciplines, 9(3). https://wac.colostate.edu/ATD/second educ/herkneretal.cfm

Ivanič, R. (2004). Discourses of writing and learning to write. Language and Education, 18(3), 220-245. https://doi.org/10.1080/09500780408666877

Kvale, S., \& Brinkmann, S. (2014). Interviews: learning the craft of qualitative research interviewing ( $3^{\text {rd }}$ ed.). Sage Publications.

Lea, M. R., \& Street, B. V. (1998). Student writing in higher education: An academic literacies approach. Studies in Higher Education, 23(2), 157-172. https://doi.org/10.1080/03075079812331380364

Lea, M. R., \& Street, B. V. (2006). The "academic literacies" model: Theory and applications. Theory Into Practice, 45(4), 368-377. https://doi.org/10.1207/s15430421tip4504 11 
Lillis, T. (2002). Student writing: Access, regulation, desire. Routledge.

Lillis, T., \& Turner, J. (2001). Student writing in higher education: contemporary confusion, traditional concerns. Teaching in Higher Education, 6(1), 57-68. https://doi.org/10.1080/13562510020029608

Marcoux, S., Marken, L. C., \& Yu, S. (2012). Establishing Peer Mentor-Led Writing Groups in Large First-Year Courses. Collected Essays on Learning and Teaching, 5, 55-64. https://doi.org/10.22329/celt.v5i0.3454

Marr, B., \& Misser, E. (2008). Writing Tutors in the Economics Classroom: A Case Study. Canadian Journal of Higher Education, 38(3), 21-36. https://doi.org/10.47678/cihe.v38i3.500

Matre, S., \& Solheim, R. (2015). Writing education and assessment in Norway: Towards shared understanding, shared language and shared responsibility. L1 Educational Studies in Language and Literature, 15, 1-33. https://doi.org/10.17239/L1ESLL-2015.15.01.05

Moberg, E. (2010). The College Writing Center: Best Practices, Best Technologies. Online Submission.

O'Neill, P. (2008). Using peer writing fellows in British universities: Complexities and possibilities. Across the Disciplines, 5. https://wac.colostate.edu/atd/fellows/oneill.cfm/

Okawa, G. Y., Fox, T., Chang, L. J. Y., Windsor, S. R., Chavez, F. B., \& Hayes, L. (2010). Multicultural Voices: Peer Tutoring and Critical Reflection in the Writing Center. The Writing Center Journal, 30(1), 40-65. www.jstor.org/stable/43442329

Prior, P., \& Bilbro, R. (2012). Academic enculturation: Developing literate practices and disciplinary identities. In M. Castelló \& C. Donahue (Eds.), University writing. Selves and texts in academic societies (pp. 19-32). Emerald Group Pub. Ltd.

Severino, C., \& Traschel, M. (2008). Theories of specialized discourses and writing fellows programs. Across the Disciplines, 5. https://wac.colostate.edu/ATD/fellows/severino.cfm

Shanahan, T., \& Shanahan, C. (2012). What is disciplinary literacy and why does it matter? Topics in language disorders, 32(1), 7-18. https://doi.org/10.1097/TLD.0b013e318244557a

Simpson, S., Clemens, R., Killingsworth, D. R., \& Ford, J. D. (2015). Creating a Culture of Communication: A Graduate-Level STEM Communication Fellows Program at a Science and Engineering University. Across the Disciplines, 12(3). https://wac.colostate.edu/docs/atd/graduate/simpsonetal2015.pdf

Topping, K. J. (2005). Trends in peer learning. Educational psychology, 25(6), 631-645. https://doi.org/10.1080/01443410500345172

Topping, K. J. (2009). Peer assessment. Theory Into Practice, 48(1), 20-27. https://doi.org/10.1080/00405840802577569

Wingate, U. (2019). 'Can you talk me through your argument'? Features of dialogic interaction in academic writing tutorials. Journal of English for Academic Purposes, 38, 25-35. https://doi.org/10.1016/i.jeap.2019.01.001 